
\title{
25 Research Square \\ Effects of sesame oil on learning and memory impairment and biomarkers of oxidative stress in rats with a long-term high-fat diet consumption
}

Mojtaba Rustaei

Hamadan University of Medical Sciences

Reihaneh Sadeghian

Shahrekord University of Medical Science

Iraj Salehi

Hamadan University of Medical Sciences

Abdolrahman Sarihi

Hamadan University of Medical Sciences

Siamak Shahidi

Hamadan University of Medical Sciences

Nafiseh Faraji

Hamadan University of Medical Sciences

Alireza Komaki ( $\square$ alirezakomaki@gmail.com )

Neurophysiology Research Center, Hamadan University of Medical Sciences, Hamadan, Iran

https://orcid.org/0000-0003-3865-9583

\section{Research Article}

Keywords: Sesame oil, Memory, Oxidative stress, High-fat diet, Passive avoidance learning, Morris water maze

Posted Date: April 19th, 2021

DOI: https://doi.org/10.21203/rs.3.rs-418705/v1

License: (c) (i) This work is licensed under a Creative Commons Attribution 4.0 International License. Read Full License 


\section{Abstract}

Nowadays, high-fat foods are eaten in most societies, which causes memory impairment and anxiety through the oxidative stress pathway. Sesame oil (SO) has potential antioxidant properties. Therefore, the effects of sesame oil on memory impairment and anxiety caused by a high-fat diet (HFD) in male rats were investigated. Eighty male Wistar rats were divided into eight groups $(n=10)$ : control (standard diet; $\mathrm{SD})$, the HFD, SD + SO $(0.5,1$, or $2 \mathrm{ml} / \mathrm{kg}$; once/day, gavage), and HFD + SO $(0.5,1$, or $2 \mathrm{ml} / \mathrm{kg}$; once/day, gavage) groups. All diets were given to the animals for three months. Finally, behavioral and oxidative stress parameters were measured. The step-through latency of retention test in SD + SO $(0.5$ or $1 \mathrm{ml} / \mathrm{kg})$ groups increased more than the control group. Also, the Barnes test on training days revealed that the latency time to find the target hole increased in the HFD group compared with the control group. Moreover, the time spent on the open arms in the SD $+S O(0.5 \mathrm{ml} / \mathrm{kg})$ group improved remarkably than the control group. Total oxidant (TOS) level in the HFD + SO $(0.5,1$, and $2 \mathrm{ml} / \mathrm{kg})$ groups was lower than the HFD group. The level of total antioxidant capacity (TAC) in the SD + SO $(2 \mathrm{ml} / \mathrm{kg})$ group was higher than the SD $+\mathrm{SO}(0.5 \mathrm{ml} / \mathrm{kg})$ group and the amount of thiol in the HFD group decreased compared with the control group. These findings suggest that the positive effects of SO on memory and anxiety are probably due to its antioxidant properties and the elimination of free radicals.

\section{Introduction}

Despite the importance of nutrients in health, there is still a lack of understanding about the true effects of a high-fat diet (HFD) on the structure and function of the central nervous system (CNS) (Moridi et al., 2020). Several studies have consistently shown that a HFD is associated with certain illnesses, such as several neurological disorders in humans and rodents (Tan and Norhaizan, 2019). In contrast, it has been shown that a HFD enhances memory in rats (Gunstad et al., 2010; Setkowicz et al., 2015; Haleem and Mahmood, 2019). However, additional studies are necessary to explain this issue.

Over the past 5 decades, the biological effects of dietary fats/oils have been considered by biomedical studies on health and diseases (Hassanzadeh-Taheri et al., 2019). One of the earliest-known eatable vegetable oils is SO derived from sesame seeds that is used as a flavor enhancer in Southeast Asia (Barnwal and Sharma, 2005). This oil is a good mixture of major unsaturated fatty acids (Gharby et al., 2017) and decreases the levels of cholesterol and inflammation in CNS disorder (Ahmad et al., 2006).

One of the vital areas associated with memory (Shahidi et al., 2019) and anxiety (Cominski et al., 2014) is the hippocampus. Some studies have demonstrated that anxiety reduces short-term memory (Humphreys and Revelle, 1984). Inversely, other studies did not find any relationship between anxiety and verbal memory performance (Waldstein et al., 1997). Also, different results have been reported on the relationship between HFD and anxiety. Kaur et al. 2017 suggested that the HFD causes anxiety (Kaur and Kaur, 2017), while other studies have reported the opposite effect (McNeilly et al., 2015). 
Oxidative stress as an imbalance between oxidant and antioxidant status is seen in a variety of CNS disorders (Ahmad et al., 2006). There is a well-known association between oxidative stress and memory deficit (Molaei et al., 2020) or anxiety (Karimi et al., 2019). Increased oxidative stress during HFD consumption appears to be associated with memory deficiency (Karimi et al., 2013). However, it is stated that $\mathrm{SO}$ is a natural product with excellent antioxidant properties (Hussain et al., 2018).

As mentioned before, our knowledge about the effects of diet on memory and anxiety is very paradoxical and limited. Also, due to the different effects of the HFD on memory and anxiety through oxidative stress pathway and the positive effects of SO with antioxidant properties, this research assessed long-term consumption effects of $\mathrm{SO}$ on memory and anxiety in rats receiving a HFD.

\section{Materials And Methods}

\section{Ethics statement}

All experimental procedures using rats were conducted in accordance with the animal care and use guidelines approved by the institutional ethics committee at Hamadan University of Medical Sciences (Ethics code: IR.UMSHA.REC.1396.576) and were performed in accordance with the National Institutes of Health Guide for Care and Use of Laboratory Animals (Care et al., 1985). All efforts were made to minimize suffering. The operations that could cause pain and distress were performed in another room in the absence of other animals.

\section{Groups}

Eighty adult male Wistar rats ( $250 \pm 50 \mathrm{~g}$ ) were obtained from the Hamadan University of Medical Sciences. All rats were held at a steady temperature $\left(22 \pm 2^{\circ} \mathrm{C}\right)$ and a dark period of 12-12 hours. They were divided into eight groups ( $n=10)$ : (1) Control group: receiving a standard diet + saline (2 cc; gavage), (2) high-fat diet group (HFD): receiving a high-fat diet + saline (2 cc; gavage), (3) standard diet group + low dose of SO (SD + SO; $0.5 \mathrm{ml} / \mathrm{kg})$ : receiving the standard diet + SO $(0.5 \mathrm{ml} / \mathrm{kg}$; gavage), (4) the standard diet group + SO (SD + SO; $1 \mathrm{ml} / \mathrm{kg}$ ): receiving the standard diet+ SO (1 ml/kg; gavage), (5) standard diet group + a high dose of SO (SD + SO $2 \mathrm{ml} / \mathrm{kg})$ : receiving the standard diet+ SO $(2 \mathrm{ml} / \mathrm{kg}$; gavage), (6) high-fat diet group + the low dose of SO (HFD + SO; $0.5 \mathrm{ml} / \mathrm{kg})$ : receiving a high-fat diet + SO (0.5 ml/kg; gavage), (7) High-fat diet group + the medium dose of SO (HFD + SO $1 \mathrm{ml} / \mathrm{kg}$ ): receiving a high-fat diet +SO (1 ml/kg; gavage), and (8) High-fat diet group + high dose of SO (HFD + SO; $2 \mathrm{ml} / \mathrm{kg}$ ): receiving a high-fat diet+ SO ( $2 \mathrm{ml} / \mathrm{kg}$; gavage).

The rats received the oil via gavage for three months/once a day (Faraji et al., 2020). All experimental procedures were carried out under the guidelines for the care and use of animals in line with agreed international animal care standards (NIH Publication No.: 85-23, revised: 1985). After receiving treatment and performing behavior tests, plasma high-density lipoprotein $(H D L)$, low-density lipoprotein $(L D L)$, triglyceride (TG), cholesterol levels, and parameters of oxidative stress were assayed. 


\section{Diet composition}

According to our other studies, the HFD was manufactured in accordance with the standard HFD D12492 regimen (Karimi et al., 2013; Faraji et al., 2020). The HFD caloric density is practically $5.24 \mathrm{kcal} / \mathrm{g}$. The standard diet of rodents in the control group contained nearly $3.0 \mathrm{kcal} / \mathrm{gr}$. The HFD is made of $60.9 \%$ fat, $3 \%$ protein, and $20.3 \%$ carbohydrates.

\section{Experimental Design}

\section{Morris water maze (MWM) test}

The MWM test is a hippocampal-dependent experiment to assess the rodents' spatial learning to distinguish between spatial memory (hidden platform) and non-spatial memory (visible platform). The training session was directed based on a previous method (Sadeghian et al., 2012; Karimi et al., 2019).

In summary, the training period comprised of 4 trials/day for four successive days. Each session started by putting the rodent in one of the four quarters. The rats were permitted to swim in the pool for 60 seconds to distinguish a hidden platform placed in one of the four quarters. If an animal did not find the platform during this period, the researcher manually guided it toward the platform. The rats' behavior in the MWM test was evaluated using parameters, such as escape latency (time to reach the platform), traveled distance, and swimming speed (motor activity) (Rezvani-Kamran et al., 2017). The probe test was performed after the fourth session by removing the platform for 60 seconds. Thirty minutes after this experiment, the platform was placed in another area above the water level, allowing rats to swim for 60 seconds and find a visible platform (Zarrinkalam et al., 2018).

\section{The novel object recognition (NOR) test}

This test includes a video recording system and a cubic open space $\left(40 \times 43 \times 35 \mathrm{~cm}^{3}\right)$. This behavioral test consists of three stages of habituation, training, and testing in 10 minutes. On the first day, a habituation session using no objects was carried out. One day later, two similar objects were placed in the chamber. Rats were permitted to detect both objects. Object exploration was monitored as placing the nose to the object at a distance of $<1 \mathrm{~cm}$ and/or touching it with the nose. On the third day, a new object was replaced with the previous object (Ganji et al., 2017).

The discrimination index (DI) was calculated by dividing the time spent exploring a new object $(\mathrm{N})$ by the total time spent exploring both objects $(\mathrm{N}+\mathrm{F}) \times 100$. Increased memory is expressed as an increase in $\mathrm{DI}$ (Shekarian et al., 2020).

\section{Barnes maze test}

The Barnes test is used to measure spatial memory. This maze consists of a dark circular platform, which is $120 \mathrm{~cm}$ in diameter with a height of $90 \mathrm{~cm}$ from the floor and contains 20 holes (10 cm in diameter) located in a circle at the edge of the platform. The target hole of this system is connected to the escape 
box $\left(10 \times 10 \times 15 \mathrm{~cm}^{3}\right)$. The stimulus is a loud buzzer sound of $80 \mathrm{~dB}$ located $50 \mathrm{~cm}$ distant from the apparatus. All test sessions were captured with a video camera. In the habituation session, the animals were given the opportunity to freely discover the device for 180 seconds until they entered the escape box. Training sessions were held for three days immediately after the habituation session. If the rats did not reach the target hole, the experimenter guided the animal toward it at the end of the experiment. The animals remained in the escape box for 60 seconds. On the fourth day (spatial learning retrieval), this method was similar to the training experiments. Delay to reach the target hole on training days, distance traveled, and a number of errors to reach the target area were recorded (Barnes, 1979; Kim et al., 2017).

\section{The Passive Avoidance Learning (PAL) test}

The training session was performed based on to our previous protocol. After the adaptation session, the training stage was performed via lowering the guillotine door and applying electrical shock (Frequency $50-\mathrm{Hz}$ square wave, $1 \mathrm{~mA}$ for $1.5 \mathrm{~s}$ ). The training was finished when the rat remained in the light chamber for 120 consecutive seconds. The latency to enter the dark compartment (step-through latency in the acquisition trial, STLa) and the number of acquisition trials (entry into the dark chamber) were recorded. The retention test was conducted 24 hours after the acquisition trial. The rats were put in the illuminated chamber, and $5 \mathrm{~s}$ later, the guillotine door was raised, and the step-through latency in the retention test (STLr) and the time spent in the dark compartment (TDC) were noted for up to $300 \mathrm{~s}$ (Zarrinkalam et al., 2016; Karimi et al., 2019; Karimi et al., 2020).

\section{Open field test}

The motor activity of the animals was assessed via this test consisting of a white acrylic field $(50 \times 50 \times 38$ $\mathrm{cm}^{3}$ ). After placing the rats in the middle of the apparatus, they were given time to explore for 10 minutes. A video camera was used to monitor the number of animals entering the center, spend time in the peripheral and central areas, and the overall distance traveled (Gharib et al., 2018; Etaee et al., 2019).

\section{Elevated plus-maze (EPM) test}

The EPM apparatus had two open arms with a surface area of $51 \times 10 \mathrm{~cm}^{2}$ and two closed arms with a surface area of $51 \times 10 \mathrm{~cm}^{2}$ and a height of $50 \mathrm{~cm}$ from the floor. Each rat was located in the center of the maze, allowing all arms to freely explore the maze for 10 minutes. The time spent in open or closed arms and the number of entries to open or closed arms were recorded (Karimi et al., 2019).

\section{The plasma extraction}

After anesthesia with urethane ( $1.8 \mathrm{~g} / \mathrm{kg}$; i.p.) at the end of the study, blood samples were taken from the portal venous system and centrifuged for 10 minutes at $3000 \mathrm{rpm}$ at $4{ }^{\circ} \mathrm{C}$. Finally, lipid profiles of the blood were determined (Molaei et al., 2020).

\section{Lipid profile assay and oxidative stress}


Thiobarbituric acid (TBA) interacts with malondialdehyde (MDA) and serves as a biomarker for oxidative damage to unsaturated fatty acids. We added $0.2 \mathrm{ml}$ of $1.8 \%$ sodium dodecyl sulfate (SDS) and $1.5 \mathrm{ml}$ of $20 \%$ acetic acid to $50 \mu \mathrm{l}$ of the sample and blended gradually. Also, $4 \mathrm{ml}$ of distilled water and the TBA ( $1.5 \mathrm{ml}$ of $0.8 \%$ aqueous solution) were heated to $95^{\circ} \mathrm{C}$ in a boiling water bath for 60 minutes, followed by adding n-butanol $(3 \mathrm{ml})$ and centrifuging at $3000 \mathrm{~g}$ for 10 minutes. The organic layer was taken and adsorption was measured at $515 \mathrm{~nm}$ using a fluorimeter. Total antioxidant capacity (TAC) was determined using the iron-lowering antioxidant power (FRAP) method, while total oxidant status (TOS) was measured by iron oxidation with orange xylene. Total thiol groups (TTGs) were determined using Elman reagent. Total cholesterol was measured using cholesterol esterase/oxidase/peroxidase reactions. The triglyceride (TG) approach was used for lipase/glycerol kinase/glycerol phosphate oxidase/peroxidase reactions. Both lipid measurements were conducted using colorimetric procedures (Pars Test Kit, Iran) (Karimi et al., 2019).

\section{Statistical analysis}

Graph Pad Prism ${ }^{\circledR} 8$ software was used to analyze the data. Biochemical parameters and behavioral studies, such as MWM, Barnes, EPM, NOR, and PAL experiments were analyzed using one-way ANOVA followed by Tukey's post hoc test. Data are presented as mean \pm standard deviation. A P $<0.05$ was considered statistically significant.

\section{Results}

\section{The comparison of MWM parameters in different groups}

The comparison of the distance traveled to find the platform on the first day of training revealed that there was a significant difference between groups $[F(7.78)=1.87, P<0.05 ;$ Fig.1.a]. The Tukey post hoc test revealed that the distance traveled in the $S D+S O(2 \mathrm{ml} / \mathrm{kg})$ group was meaningfully higher than the HFD group $(P<0.05)$. The distance traveled markedly decreased in the HFD+SO $(2 \mathrm{ml} / \mathrm{kg})$ group compared with the SD+SO $(1 \mathrm{ml} / \mathrm{kg})$ group $(P<0.05)$. The comparison of the distance traveled to find the platform on the second day of training declared a significant difference between groups $[F(7,78)=1.89$, $P<0.05]$. According to the Tukey post hoc test, the HFD group had a shorter traveled distance to find the platform than the control group $(P<0.01)$. This parameter in the $\mathrm{SD}+\mathrm{SO}(1 \mathrm{ml} / \mathrm{kg})$ group significantly increased compared with the HFD group $(P<0.01)$. The traveled distance in the HFD+SO $(1 \mathrm{ml} / \mathrm{kg})$ group was longer than the HFD group $(P<0.05)$.

The comparison of the distance traveled to find the platform on the third day of training revealed a significant difference between the groups $[F(7,78)=0.80, P<0.05]$. The $S D+S O(0.5 \mathrm{ml} / \mathrm{kg})$ group was found with a longer distance to find the platform than the control group on the third day $(P<0.05)$. No significant differences were found between groups on the fourth day of training (Fig.1.a).

The comparison of the time spent in the target quadrant in the probe test did not show a significant difference between the groups $[F(7.78)=1.184, P=0.323$; Fig.2.a]. The escape latency time to find the 
platform in the visible test on the test day revealed that there was no significant difference between the groups $[F(7,78)=0.968, P=0.461 ; F i g .2 . b]$. Also, regarding the time spent in the target zone in the working test, there was no significant difference between groups $[F(7,78)=0.805, P=0.586$; Fig.2.c].

\section{The comparison of training days between groups in the Barnes Maze Test}

There were no significant differences between groups in the escape latency time to reach the target point at different times $(P=0.004)$. On the first day, all groups were found with a significant difference from the control group ( $P<0.005 ;$ Fig.3.a). On the second day, there was a significant difference between the HFD, $\mathrm{SD}+\mathrm{SO}(0.5 \mathrm{ml} / \mathrm{kg}), \mathrm{HFD}+\mathrm{SO}(0.5 \mathrm{ml} / \mathrm{kg})$, and HFD+SO $(2 \mathrm{ml} / \mathrm{kg})$ groups compared with the control group $(P<0.005 ;$ Fig.3.a). On the third day, there was a significant difference between the HFD, HFD + SO $(0.5 \mathrm{ml} / \mathrm{kg}), \mathrm{HFD}+\mathrm{SO}(1 \mathrm{ml} / \mathrm{kg})$, and HFD + SO $(2 \mathrm{ml} / \mathrm{kg})$ groups compared with the control group ( $P$ $<0.005$; Fig.3.a). The mean distance traveled in the target quadrant was not remarkably different between groups on the test day $(P=0.218 ;$ Fig.3.b]. There was no significant difference in the number of errors to find the target zone on the test day between the groups $(P=0.083$; Fig.3.c]

\section{The results of object recognition test in different groups}

The discrimination performance showed no significant reduction between groups $[\mathrm{F}(7.70)=1.701, P=$ 0.125; Fig.4].

\section{The comparison of the passive avoidance memory parameters in different groups}

The comparison of the delay in the first entry into the darkness during the training phase did not differ between the groups $[F(7,61)=1.899, P=0.088 .5$. a]. Also, the comparison of the number of shocks received on the training day did not show a significant difference between the groups $[F(7.61)=0.865$, $P=0.54$; Fig.5.b].

The comparison of the delay in the first entry into darkness on the day of the test revealed a significant difference between the groups $[\mathrm{F}(7,62)=5.577, P<0.001$; Fig.5.c]. Tukey post hoc test revealed that the delay in the first entry into darkness on the day of the test markedly decreased in the control group than the HFD $(P<0.001), \mathrm{SD}+\mathrm{SO}(0.5 \mathrm{ml} / \mathrm{kg})(P<0.001), \mathrm{SD}+\mathrm{SO}(1 \mathrm{ml} / \mathrm{kg})(P<0.01), \mathrm{HFD}+\mathrm{SO}(0.5 \mathrm{ml} / \mathrm{kg})$ $(P<0.05)$, and HFD + SO $(1 \mathrm{ml} / \mathrm{kg})(P<0.01)$ groups. The latency of the first entry into the darkness on the day of the test markedly increased in the SD $+\mathrm{SO}(1 \mathrm{ml} / \mathrm{kg})$ group than in the $\mathrm{SD}+\mathrm{SO}(2 \mathrm{ml} / \mathrm{kg})$ $(P<0.001)$ and HFD $+\mathrm{SO}(2 \mathrm{ml} / \mathrm{kg})$ groups $(P<0.01)$. The latency of the first entry into darkness on the day of the test markedly decreased in the SD $+\mathrm{SO}(2 \mathrm{ml} / \mathrm{kg})$ group than the HFD $(P<0.001)$, SD $+\mathrm{SO}(0.5$ $\mathrm{ml} / \mathrm{kg})(P<0.001), \mathrm{SD}+\mathrm{SO}(1 \mathrm{ml} / \mathrm{kg})(P<0.001), \mathrm{HFD}+\mathrm{SO}(0.5 \mathrm{ml} / \mathrm{kg})(P<0.05)$, and HFD + SO $(1 \mathrm{ml} / \mathrm{kg})$ $(P<0.01)$ groups (Fig.5.C). The comparison of the time spent in the dark chamber on the test day revealed a significant difference between the groups $[F(7,62)=2.665, P=0.019]$. The time spent in the dark chamber in the $S D+S O(2 \mathrm{ml} / \mathrm{kg})$ group was markedly higher than other groups $[P<0.001 ;$ Fig.5.d].

\section{The comparison of motor activity in different groups}


The groups showed no significant difference in motor activity $[\mathrm{F}(7,78)=1.929, P=0.07$; Fig.6].

\section{The comparison of the entries into open arms of the elevated plus-maze in different groups}

The comparison of time spent in open arms showed a significant difference between groups $[\mathrm{F}(7.76)=$ $2.438, P<0.05]$. Tukey post hoc test revealed that the time spent in the open arms in the control group was markedly less than the HFD group $(P<0.001)$ and the $S D+S O(0.5 \mathrm{ml} / \mathrm{kg})$ group $(P<0.05)$. Also, the HFD group spent more time in the open arms compared with the SD + SO $(1 \mathrm{ml} / \mathrm{kg})(P<0.01), \mathrm{SD}+\mathrm{SO}(2$ $\mathrm{ml} / \mathrm{kg})(P<0.05), \mathrm{HFD}+\mathrm{SO}(0.5 \mathrm{ml} / \mathrm{kg}), \mathrm{HFD}+\mathrm{SO}(0.5 \mathrm{ml} / \mathrm{kg})(P<0.05), \mathrm{HFD}+\mathrm{SO}(1 \mathrm{ml} / \mathrm{kg})(P<0.01)$, and $\mathrm{HFD}+\mathrm{SO}(2 \mathrm{ml} / \mathrm{kg})(P<0.05)$ groups (Fig.7.a)

Also, the comparison of the number of entries into open arms of EPM revealed a significant difference between the groups $[F(7.76)=2.588, P<0.05]$. The number of entries into open arms in the SD + SO 2 $\mathrm{ml} / \mathrm{kg}$ group was markedly more than the control $(P<0.05), \operatorname{HFD}(P<0.05), \mathrm{SD}+\mathrm{SO}(0.5 \mathrm{ml} / \mathrm{kg})(P<0.01)$, $\mathrm{SD}+\mathrm{SO}(1 \mathrm{ml} / \mathrm{kg})(P<0.01)$, and HFD + SO $(1 \mathrm{ml} / \mathrm{kg})(P<0.05)$ groups. The number of entries into open arms in the HFD + SO $(0.5 \mathrm{ml} / \mathrm{kg})$ and HFD $+\mathrm{SO}(0.5 \mathrm{ml} / \mathrm{kg})$ groups was noticeably more than the SD + SO $(0.5 \mathrm{ml} / \mathrm{kg})(P<0.01)$ and SD $+\mathrm{SO}(1 \mathrm{ml} / \mathrm{kg})$ groups $(P<0.05)$. The number of entries into open arms in the HFD + SO $(0.5 \mathrm{ml} / \mathrm{kg})$ and HFD + SO $(0.5 \mathrm{ml} / \mathrm{kg})$ groups was remarkably more than the SD + SO $(0.5$ $\mathrm{ml} / \mathrm{kg})(P<0.05)$ and HFD + SO $(1 \mathrm{ml} / \mathrm{kg})(P<0.05)$ groups (Fig.7.b)

\section{The comparison of the levels of cholesterol, triglyceride, LDL, and HDL between different groups}

The Comparison of levels of cholesterol did not show a significant difference between groups $[\mathrm{F}(7.47)=$ 1.083, $P=0.392 ;$ Fig.8.a]. However, the one-way ANOVA results revealed a significant difference between the groups in TG levels $[\mathrm{F}(7.47)=3.88, P<0.01$; Fig.8.b]. Tukey's Post hoc test revealed that the $\mathrm{SD}+\mathrm{SO}$ $(0.5 \mathrm{ml} / \mathrm{kg})$ group had remarkably higher TG levels than the control $(P<0.01)$ and HFD $(P<0.001)$ groups. In addition, the groups receiving normal diet and a low-dose oil showed a noticeably higher TG levels than the SD+SO $(1 \mathrm{ml} / \mathrm{kg})(P<0.001), \mathrm{SD}+\mathrm{SO}(2 \mathrm{ml} / \mathrm{kg})(P<0.001), \mathrm{HFD}+\mathrm{SO}(0.5 \mathrm{ml} / \mathrm{kg})(P<0.001)$, and HFD+SO $(1 \mathrm{ml} / \mathrm{kg})(P<0.01)$ groups. The level of TG in the HFD+SO $(2 \mathrm{ml} / \mathrm{kg})$ group was noticeably higher than the HFD group and lower than the SD+SO $(0.5 \mathrm{ml} / \mathrm{kg})$ group $(P<0.05)$.

The comparison of LDL level did not show a significant difference between groups $[\mathrm{F}(7,47)=2.18, P=$ 0.056; Fig.8.c]. However, the comparison of the HDL levels revealed a significant difference between groups $[F(7,47)=)=3.917, P<0.01$; Fig.8.d]. Tukey's post hoc test revealed that the HDL levels in the control group was noticeably lower than the SD + SO $(0.5 \mathrm{ml} / \mathrm{kg})(P<0.001), \mathrm{SD}+\mathrm{SO}(1 \mathrm{ml} / \mathrm{kg})(P<0.05)$, $\mathrm{SD}+\mathrm{SO}(2 \mathrm{ml} / \mathrm{kg})(P<0.05), \mathrm{HFD}+\mathrm{SO}(0.5 \mathrm{ml} / \mathrm{kg}), \mathrm{HFD}+\mathrm{SO}(0.5 \mathrm{ml} / \mathrm{kg})(P<0.001), \mathrm{HFD}+\mathrm{SO}(1 \mathrm{ml} / \mathrm{kg})$, $(P<0.01)$, and HFD + SO $(2 \mathrm{ml} / \mathrm{kg})(P<0.01)$ groups. It also revealed that the levels of HDL in the HFD group was noticeably lower than the SD + SO $(0.5 \mathrm{ml} / \mathrm{kg})(P<0.01), \mathrm{HFD}+\mathrm{SO}(0.5 \mathrm{ml} / \mathrm{kg})(P<0.01), \mathrm{HFD}+$ SO $(1 \mathrm{ml} / \mathrm{kg})(P<0.05)$ and the HFD + SO $(2 \mathrm{ml} / \mathrm{kg})(P<0.05)$ groups (Fig.8).

The comparison of the levels of MDA, TOS, TAC, and thiol in different groups 
The comparison of MDA levels did not show a significant difference between groups $[\mathrm{F}(7.47)=1.17, P=$ 0.371; Fig.9.a]. However, TOS content showed a significant difference between groups $[F(7.47)=2.52$, $P<0.05]$. Tukey post hoc test revealed that the amount of TOS in the HFD group was noticeably higher than the control $(P<0.01), \mathrm{SD}+\mathrm{SO}(0.5 \mathrm{ml} / \mathrm{kg})(P<0.05), \mathrm{SD}+\mathrm{SO}(1 \mathrm{ml} / \mathrm{kg})(P<0.05), \mathrm{SD}+\mathrm{SO}(2 \mathrm{ml} / \mathrm{kg})$ $(P<0.01), \mathrm{HFD}+\mathrm{SO}(0.5 \mathrm{ml} / \mathrm{kg})(P<0.01), \mathrm{HFD}+\mathrm{SO}(1 \mathrm{ml} / \mathrm{kg})(P<0.01)$, and HFD $+\mathrm{SO}(2 \mathrm{ml} / \mathrm{kg})(P$ $<0.05)$ groups (Fig.9.b).

The comparison of the level of TAC revealed a significant difference between groups $[F(7.47)=2.601$, $P<0.05]$. Tukey post hoc test revealed that the amount of TAC in the SD $+\mathrm{SO}(2 \mathrm{ml} / \mathrm{kg})$ group was noticeably higher than the HFD $(P<0.05), \mathrm{SD}+\mathrm{SO}(0.5 \mathrm{ml} / \mathrm{kg})(P<0.05), \mathrm{HFD}+\mathrm{SO}(0.5 \mathrm{ml} / \mathrm{kg})(P<0.01)$, $\mathrm{HFD}+\mathrm{SO}(1 \mathrm{ml} / \mathrm{kg}$ group $(P<0.05)$, and HFD $+\mathrm{SO}(2 \mathrm{ml} / \mathrm{kg})(P<0.05)$ groups. Also, the amount of TAC in the SD + SO $(1 \mathrm{ml} / \mathrm{kg})$ group was noticeably higher than the HFD $(P<0.05)$ and HFD + SO $(0.5 \mathrm{ml} / \mathrm{kg})$ $(P<0.05)$ groups (Fig.9.c).

The comparison of thiol levels revealed a significant difference between groups $[F(7,47)=5.587$, $P<0.001]$. Tukey post hoc test revealed that the amount of thiol in the control group was noticeably higher than the HFD $(P<0.001), \mathrm{SD}+\mathrm{SO}(0.5 \mathrm{ml} / \mathrm{kg})(P<0.001), \mathrm{SD}+\mathrm{SO}(1 \mathrm{ml} / \mathrm{kg})(P<0.01), \mathrm{SD}+\mathrm{SO}(2 \mathrm{ml} / \mathrm{kg})$ $(P<0.01), \mathrm{HFD}+\mathrm{SO}(0.5 \mathrm{ml} / \mathrm{kg})(P<0.001), \mathrm{HFD}+\mathrm{SO}(1 \mathrm{ml} / \mathrm{kg})(P<0.001)$ and HFD $+\mathrm{SO}(2 \mathrm{ml} / \mathrm{kg})(P$ $<0.01)$ groups. Also, the amount of thiol in the $S D+S O(0.5 \mathrm{ml} / \mathrm{kg})$ group was noticeably higher than the $\mathrm{SD}+\mathrm{SO}(1 \mathrm{ml} / \mathrm{kg})(P<0.05), \mathrm{SD}+\mathrm{SO}(2 \mathrm{ml} / \mathrm{kg})(P<0.001)$, and HFD + SO $(0.5 \mathrm{ml} / \mathrm{kg})(P<0.01)$ groups (Fig.9.d).

\section{Discussion}

The effects of long-term consumption of the HFD and SO on memory and anxiety through oxidative stress pathways were assessed in this study. The key results of the study were as follows: (1) Our results showed that the administration of SO and HFD did not affect cholesterol and LDL levels; however, SO treatment caused significant changes in TG and HDL levels; (2) the HFD increased TOS and decreased TAC and thiol compared with the control group; (3) SO has antioxidant properties evidenced by increasing TAC and decreasing TOS; (4) the HFD group spent more time in the open arms than the control group; (5) SO showed two opposite effects in the passive avoidance test; and (6) the HFD+ SO (1 ml/kg) group was found with longer traveled distance than the HFD group in the MWM, which means that SO had a negative effect on memory.

The effects of SO on lipid profiles differ based on its dose different variables (Hsu and Parthasarathy, 2017). Our results showed that the administration of SO and HFD did not have a significant effect on cholesterol. Zhou et al. (2017) observed that the serum cholesterol level of HFD rats noticeably increased after 4 and 8 weeks compared with the control group (Zhou et al., 2017). Inversely, the level of cholesterol reduced during the use of the SO-containing diet (Narasimhulu et al., 2015).

Based on our findings, none of the HFD and SO groups were found with significant changes in LDL levels. This finding is in contrast to the results reported by Wang et al. (2014), who revealed an increase in LDL 
following the HFD treatment (Wang et al., 2014). Consistent with our results, SO administration for one month after a three-month period of atherogenic diet did not change cholesterol, TG, and LDL levels (Narasimhulu et al., 2018).

SO increased TG level; however, the HFD had no effect on TG levels. This is not consistent with the results of Asgary et al. (2013) who found that the HFD group showed an increase in TG level compared with the control group; however, SO treatment had no effect on the TG level of the HFD + SO group compared with the HFD group (Asgary et al., 2013). These differences may be due to the presence of 19 types of TG (Ding et al., 2014).

According to the results, the level of $\mathrm{HDL}$ in SD+ SO groups (all doses) was higher than the control group, which means that $\mathrm{SO}$ increases the level of HDL. Also, the level of HDL in HFD+SO groups (all doses) was higher than HFD, which means that SO increased the level of HDL even in combination with HFD. Therefore, SO is probably effective for cardiovascular health (Guo et al., 2017).

The comparison of MDA content did not show a significant difference between groups. Consistent with our study, Tabari et al. (2016) revealed that SO treatment did not change MDA levels compared with the control group (Tabari et al., 2016). Inversely, the serum MDA levels of the rats with HFD-induced obesity were noticeably higher than the control group (Wu et al., 2016).

The HFD acts as an inducer of oxidative stress by increasing TOS and decreasing TAC and thiol levels compared with the control group. Inversely, SO at all three doses has antioxidant properties by increasing TAC level and decreasing TOS level. In line with our study, a significant decrease in glutathione peroxidase (GPX) (Sripradha et al., 2016) and an increase in TOS level in the HFD group were reported (Maithilikarpagaselvi et al., 2016). Thiol level in the groups receiving the SD+SO decreased compared with the control group. Another study revealed the protective effects of high doses of SO against scopolamine-induced amnesia, in which GPX levels decreased compared with the sham group (Tabari et al., 2016).

Our results demonstrated the HFD group spent more time in the open arms of the NOR test than the control group, which indicates that the HFD reduces the anxiety that can be caused by affecting the hypothalamic-pituitary-adrenal axis function (McNeilly et al., 2015). Also, our results indicated that SO alone has an anti-anxiety effect, but when it is consumed with the HFD, it induces anxiety. This effect is possibly caused by inhibiting beta-adrenoceptor receptors type 1 in the amygdala region. Kesmati et al. (2014) concluded that the intraperitoneal injection of SO induced anxiety behaviors in rats (Kesmati et al., 2014).

SO exhibited two opposite effects in the passive avoidance test. Thus, the SD had a positive effect and the HFD had a negative effect on memory. Some studies have demonstrated that the HFD, even for a short period of life can potentially disrupt a number of behavioral tests of learning and memory, while sesame seed extract reduced acetylcholinesterase activity and the level of BAX and caspase 3 (Chidambaram et al., 2016). Thus, the results are inconsistent due to the differences in research designs, 
and length of HFD exposure during critical periods of development, specific types of fatty acids, and gender (Cordner and Tamashiro, 2015).

Distance traveled in the HFD+ SO $(1 \mathrm{ml} / \mathrm{kg})$ group was longer than the HFD group in MWM test, which means that $\mathrm{SO}$ in the presence of a HFD has a negative effect on memory. The $S D+S O(0.5 \mathrm{ml} / \mathrm{kg})$ group was found with a longer distance traveled to find the platform than the control group. SO at a low dose has disrupted learning on second or third days. There was no significant difference between groups on the fourth day of training and probe test. The results obtained from the learning days in the MWM regarding the positive effect of the HFD are consistent with the positive effect of the HFD on memory, which may be attributed to an increase in ketone bodies (Setkowicz et al., 2015).

\section{Conclusion}

According to our findings, the HFD induced oxidative stress by increasing TOS level and decreasing TAC and thiol levels. In contrast, SO due to its antioxidant properties, was able to increase TAC level. Inducing oxidative stress increased the escape latency time to find the target zone in the HFD group compared with the control group in the Barnes test. SO may also increase STLr compared with the control group and improve passive avoidance memory through its antioxidant properties. Also, SO was able to increase the time spent in the open arm of the EPM compared with the control group because of its anti-anxiety effect.

\section{Declarations}

\section{Authors' contributions}

All authors have assumed responsibility for data integrity and accuracy of the data analysis. Study concept and design: MR, RS, AK. Data acquisition: MR, IS. Data analysis and interpretation: AS, SS, NF, AK. Drafting of the manuscript: AK, RS. Critical revision of the manuscript for important intellectual content: AK and IS. Study supervision: AK. All authors read and approved the final manuscript.

\section{Data availability statements}

The authors declare that the data supporting the findings of this study are available within the article [and its supplementary information files].

\section{Acknowledgments}

The authors would like to express their gratitude to the staff of the Neurophysiology Research Center for helping us to carry out this project. This study was supported by a grant (Grant number: 9609075620) of the Hamadan University of Medical Sciences, Hamadan, Iran.

\section{Compliance with ethical standards}

\section{Conflict of interest statement}


We confirm that the authors do not have any conflict of interest with this publication.

\section{References}

Ahmad S, Yousuf S, Ishrat T, Khan M, Bhatia K, Fazli I, Khan J, Ansari N, Islam F. 2006. Effect of dietary sesame oil as antioxidant on brain hippocampus of rat in focal cerebral ischemia. Life sciences 79:19211928.

Asgary S, Rafieian-Kopaei M, Najafi S, Heidarian E, Sahebkar A. 2013. Antihyperlipidemic effects of Sesamum indicum L. in rabbits fed a high-fat diet. ScientificWorldJournal 2013:365892.

Barnes CA. 1979. Memory deficits associated with senescence: a neurophysiological and behavioral study in the rat. J Comp Physiol Psychol 93:74-104.

Barnwal BK, Sharma MP. 2005. Prospects of biodiesel production from vegetable oils in India. Renewable and Sustainable Energy Reviews 9:363-378.

Care loLARCo, Animals UoL, Resources NloHDoR. 1985. Guide for the care and use of laboratory animals: National Academies.

Chidambaram SB, Pandian A, Sekar S, Haridass S, Vijayan R, Thiyagarajan LK, Ravindran J, Balaji Raghavendran HR, Kamarul T. 2016. Sesame indicum, a nutritional supplement, elicits antiamnesic effect via cholinergic pathway in scopolamine intoxicated mice. Environ Toxicol 31:1955-1963.

Cominski TP, Jiao X, Catuzzi JE, Stewart AL, Pang KCH. 2014. The role of the hippocampus in avoidance learning and anxiety vulnerability. Frontiers in behavioral neuroscience 8:273-273.

Cordner ZA, Tamashiro KL. 2015. Effects of high-fat diet exposure on learning \& memory. Physiol Behav 152:363-371.

Ding L, Zhang C, Masood A, Li J, Sun J, Nadeem A, Zhang H-T, O’Donnell JM, Xu Y. 2014. Protective effects of phosphodiesterase 2 inhibitor on depression-and anxiety-like behaviors: involvement of antioxidant and anti-apoptotic mechanisms. Behavioural brain research 268:150-158.

Etaee F, Komaki A, Faraji N, Rezvani-Kamran A, Komaki S, Hasanein P, Taheri M, Omidi G. 2019. The effects of cinnamaldehyde on acute or chronic stress-induced anxiety-related behavior and locomotion in male mice. Stress 22:358-365.

Faraji N, Ganji A, Heshami N, Salehi I, Haddadian A, Shojaie S, Komaki A. 2020. Hypolipidemic effects of Hypericum Scabrum extract on the serum lipid profile and obesity in high-fat diet fed rats. Hum Antibodies.

Ganji A, Salehi I, Nazari M, Taheri M, Komaki A. 2017. Effects of Hypericum scabrum extract on learning and memory and oxidant/antioxidant status in rats fed a long-term high-fat diet. Metabolic brain disease 
Gharby S, Harhar H, Bouzoubaa Z, Asdadi A, El Yadini A, Charrouf Z. 2017. Chemical characterization and oxidative stability of seeds and oil of sesame grown in Morocco. Journal of the Saudi Society of Agricultural Sciences 16:105-111.

Gharib A, Sayyahi Z, Komaki A, Barkley V, Sarihi A, Mirnajafi-Zadeh J. 2018. The role of 5-HT(1A) receptors of hippocampal CA1 region in anticonvulsant effects of low-frequency stimulation in amygdala kindled rats. Physiol Behav 196:119-125.

Gunstad J, Lhotsky A, Wendell CR, Ferrucci L, Zonderman AB. 2010. Longitudinal Examination of Obesity and Cognitive Function: Results from the Baltimore Longitudinal Study of Aging. Neuroepidemiology 34:222-229.

Guo H, Ban YH, Cha Y, Kim TS, Lee SP, Suk An E, Choi J, Woom Seo D, Yon JM, Choi EK, Kim YB. 2017. Comparative effects of plant oils and trans-fat on blood lipid profiles and ischemic stroke in rats. $J$ Biomed Res 31:122-129.

Haleem DJ, Mahmood K. 2019. Brain serotonin in high-fat diet-induced weight gain, anxiety and spatial memory in rats. Nutritional Neuroscience:1-10.

Hassanzadeh-Taheri M, Hassanzadeh-Taheri M, Jahani F, Erfanian Z, Moodi H, Hosseini M. 2019. The impact of long-term consumption of diets enriched with olive, cottonseed or sesame oils on kidney morphology: A stereological study. An Acad Bras Cienc 91:e20180855.

Hsu E, Parthasarathy S. 2017. Anti-inflammatory and Antioxidant Effects of Sesame Oil on Atherosclerosis: A Descriptive Literature Review. Cureus 9:e1438.

Humphreys MS, Revelle W. 1984. Personality, motivation, and performance: a theory of the relationship between individual differences and information processing. Psychological review 91:153.

Hussain SA, Hameed A, Ajmal I, Nosheen S, Suleria HAR, Song Y. 2018. Effects of sesame seed extract as a natural antioxidant on the oxidative stability of sunflower oil. Journal of food science and technology 55:4099-4110.

Karimi SA, Salehi I, Komaki A, Sarihi A, Zarei M, Shahidi S. 2013. Effect of high-fat diet and antioxidants on hippocampal long-term potentiation in rats: An in vivo study. Brain Research 1539:1-6.

Karimi SA, Salehi I, Shykhi T, Zare S, Komaki A. 2019. Effects of exposure to extremely low-frequency electromagnetic fields on spatial and passive avoidance learning and memory, anxiety-like behavior and oxidative stress in male rats. Behav Brain Res 359:630-638.

Karimi SA, Salehi I, Taheri M, Faraji N, Komaki A. 2020. Effects of Regular Exercise on Diabetes-Induced Memory Deficits and Biochemical Parameters in Male Rats. Journal of Molecular Neuroscience:1-8. 
Kaur T, Kaur G. 2017. Withania somnifera as a potential candidate to ameliorate high fat diet-induced anxiety and neuroinflammation. J Neuroinflammation 14:201.

Kesmati M, Mard-Soltani M, Khajehpour L. 2014. Anxiogenic Effects of Acute Injection of Sesame oil May be Mediated by $\beta-1$ Adrenoceptors in the Basolateral Amygdala. Adv Pharm Bull 4:35-42.

Kim DJ, St Louis N, Molaro RA, Hudson GT, Chorley RC, Anderson BJ. 2017. Repeated unpredictable threats without harm impair spatial working memory in the Barnes maze. Neurobiol Learn Mem 137:92100 .

Maithilikarpagaselvi N, Sridhar MG, Swaminathan RP, Sripradha R. 2016. Preventive effect of curcumin on inflammation, oxidative stress and insulin resistance in high-fat fed obese rats. $\mathrm{J}$ Complement Integr Med 13:137-143.

McNeilly AD, Stewart CA, Sutherland C, Balfour DJ. 2015. High fat feeding is associated with stimulation of the hypothalamic-pituitary-adrenal axis and reduced anxiety in the rat. Psychoneuroendocrinology 52:272-280.

Molaei A, Hatami H, Dehghan G, Sadeghian R, Khajehnasiri N. 2020. Synergistic effects of quercetin and regular exercise on the recovery of spatial memory and reduction of parameters of oxidative stress in animal model of Alzheimer's disease. EXCLI journal 19:596-612.

Moridi H, Sarihi A, Habibitabar E, Shateri H, Salehi I, Komaki A, Karimi J, Karimi SA. 2020. Effects of posttraining administration of LY341495, as an mGluR2/3 antagonist on spatial memory deficit in rats fed with high-fat diet. IBRO reports 9:241-246.

Narasimhulu CA, Riad A, Parthasarathy S. 2018. Sesame Oil and an Aqueous Extract Derived from Sesame Oil Enhance Regression of Preexisting Atherosclerotic Lesions in Low-Density Lipoprotein Receptor Knockout Mice. J Med Food 21:641-646.

Narasimhulu CA, Selvarajan K, Litvinov D, Parthasarathy S. 2015. Anti-atherosclerotic and antiinflammatory actions of sesame oil. J Med Food 18:11-20.

Rezvani-Kamran A, Salehi I, Shahidi S, Zarei M, Moradkhani S, Komaki A. 2017. Effects of the hydroalcoholic extract of Rosa damascena on learning and memory in male rats consuming a high-fat diet. Pharmaceutical biology 55:2065-2073.

Sadeghian R, Fereidoni M, Soukhtanloo M, Azizi-Malekabadi H, Hosseini M. 2012. Decreased nitric oxide levels in the hippocampus may play a role in learning and memory deficits in ovariectomized rats treated by a high dose of estradiol. Arq Neuropsiquiatr 70:874-879.

Setkowicz Z, Gaździńska A, Osoba JJ, Karwowska K, Majka P, Orzeł J, Kossowski B, Bogorodzki P, Janeczko K, Wyleżoł M, Gazdzinski SP. 2015. Does Long-Term High Fat Diet Always Lead to Smaller 
Hippocampi Volumes, Metabolite Concentrations, and Worse Learning and Memory? A Magnetic Resonance and Behavioral Study in Wistar Rats. PLoS One 10:e0139987.

Shahidi S, Komaki A, Sadeghian R, Asl SS. 2019. Different doses of methamphetamine alter long-term potentiation, level of BDNF and neuronal apoptosis in the hippocampus of reinstated rats. J Physiol Sci 69:409-419.

Shekarian M, Komaki A, Shahidi S, Sarihi A, Salehi I, Raoufi S. 2020. The protective and therapeutic effects of vinpocetine, a PDE1 inhibitor, on oxidative stress and learning and memory impairment induced by an intracerebroventricular (ICV) injection of amyloid beta $(a \beta)$ peptide. Behav Brain Res 383:112512.

Sripradha R, Sridhar MG, Maithilikarpagaselvi N. 2016. Antihyperlipidemic and antioxidant activities of the ethanolic extract of Garcinia cambogia on high fat diet-fed rats. J Complement Integr Med 13:9-16.

Tabari SS, Babri S, Mirzaie F, Farajdokht F, Mohaddes G. 2016. Enduring amnesia induced by ICV scopolamine is reversed by sesame oil in male rats. Acta Cir Bras 31:520-526.

Tan BL, Norhaizan ME. 2019. Effect of High-Fat Diets on Oxidative Stress, Cellular Inflammatory Response and Cognitive Function. Nutrients 11:2579.

Waldstein SR, Ryan CM, Jennings JR, Muldoon MF, Manuck SB. 1997. Self-reported levels of anxiety do not predict neuropsychological performance in healthy men. Archives of Clinical Neuropsychology 12:567-574.

Wang YX, Li Y, Sun AM, Wang FJ, Yu GP. 2014. Hypolipidemic and antioxidative effects of aqueous enzymatic extract from rice bran in rats fed a high-fat and -cholesterol diet. Nutrients 6:3696-3710.

Wu P, Zhang F, Dai Y, Han L, Chen S. 2016. Serum TNF-a, GTH and MDA of high-fat diet-induced obesity and obesity resistant rats. Saudi Pharm J 24:333-336.

Zarrinkalam E, Heidarianpour A, Salehi I, Ranjbar K, Komaki A. 2016. Effects of endurance, resistance, and concurrent exercise on learning and memory after morphine withdrawal in rats. Life sciences 157:19-24.

Zarrinkalam E, Ranjbar K, Salehi I, Kheiripour N, Komaki A. 2018. Resistance training and hawthorn extract ameliorate cognitive deficits in streptozotocin-induced diabetic rats. Biomedicine \& Pharmacotherapy 97:503-510.

Zhou X, Ren F, Wei H, Liu L, Shen T, Xu S, Wei J, Ren J, Ni H. 2017. Combination of berberine and evodiamine inhibits intestinal cholesterol absorption in high fat diet induced hyperlipidemic rats. Lipids Health Dis 16:239.

\section{Figures}



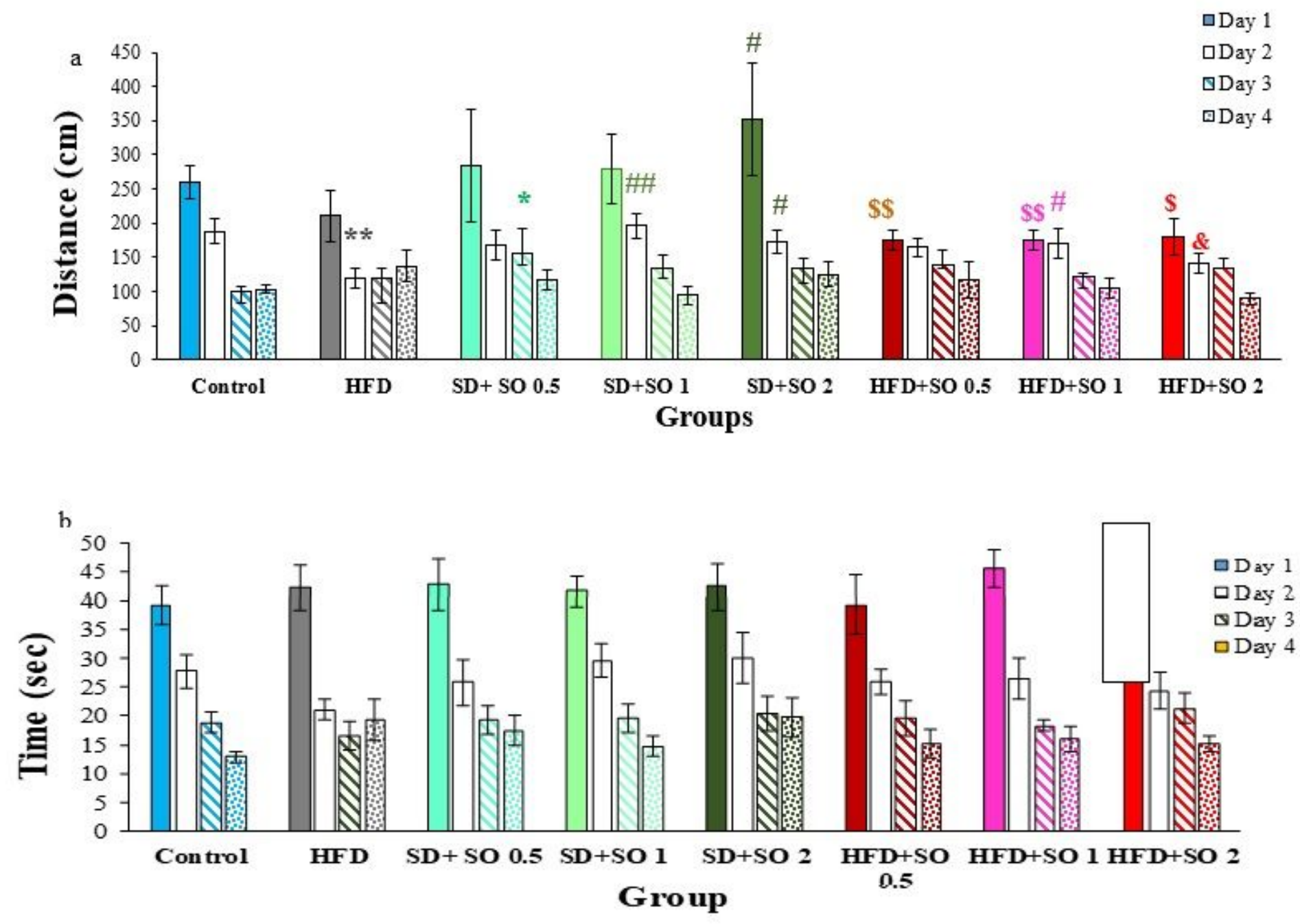

Figure 1

Comparison of (a) the distance traveled, (b) escape latency for finding the platform in the training days of Morris water maze task ( $n=10$ each group). Data are expressed as mean \pm standard deviation. ${ }^{*}<0.05$ and ${ }^{* * P}<0.01$ compared with the control group. $\# \mathrm{P}<0.05$ and $\# \# \mathrm{P}<0.01$ compared with the high-fat diet (HFD) group. $\$ \$ P<0.01$ compared with the HFD group + high dose of sesame oil (HFD + SO; $2 \mathrm{ml} / \mathrm{kg}) . \& \&$ $\mathrm{P}<0.01$ compared with the HFD group + low dose of sesame oil (HFD $+S 0 ; 0.5 \mathrm{ml} / \mathrm{kg})$. 

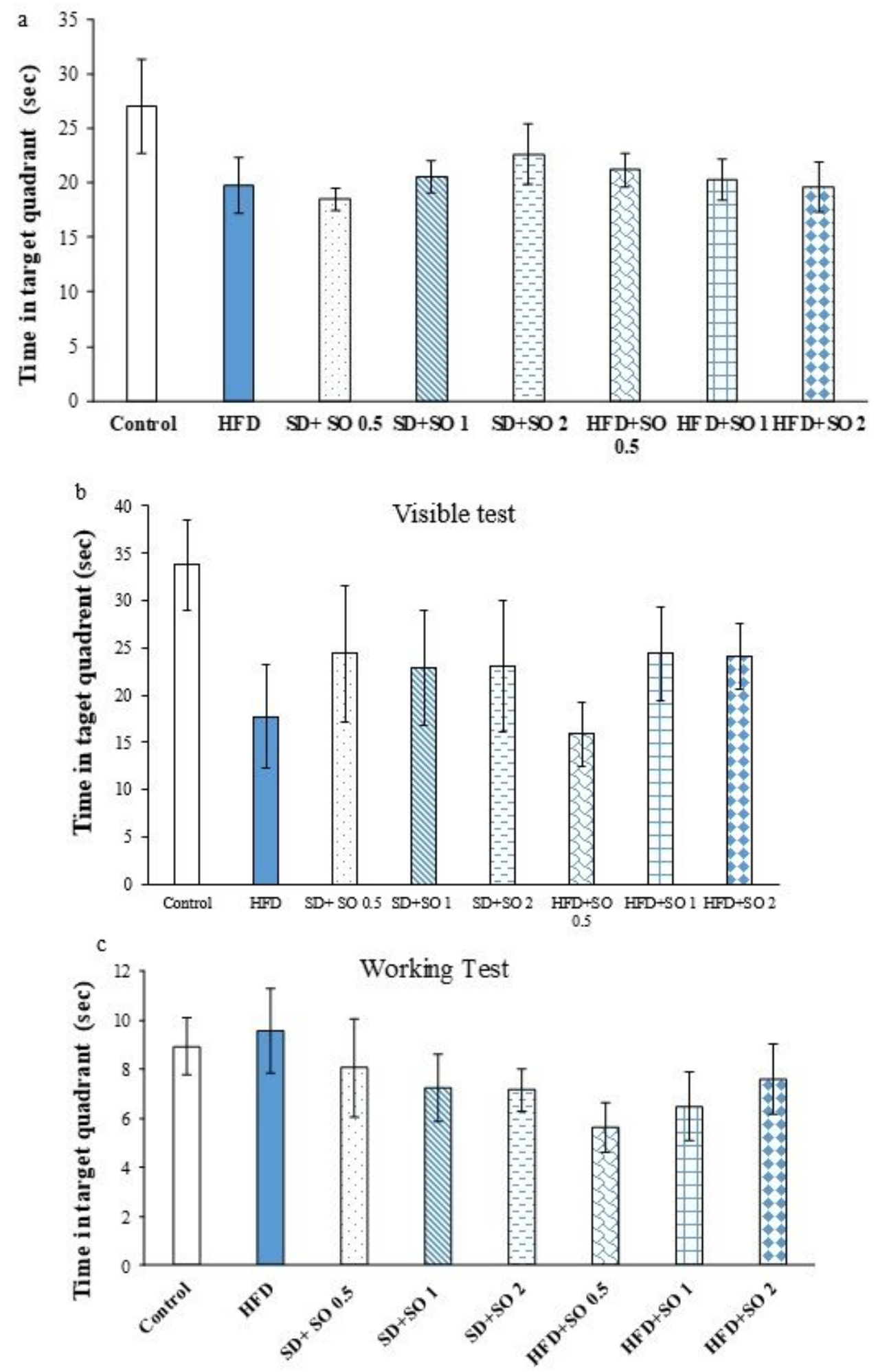

Figure 2

Comparison of (a) time spent in the target quadrant in the probe test, (b) Escape latency to find a visible platform. (c) Escape latency to find the hidden platform in the Morris water maze task ( $n=10$ each group). Data are expressed as mean \pm standard deviation. 

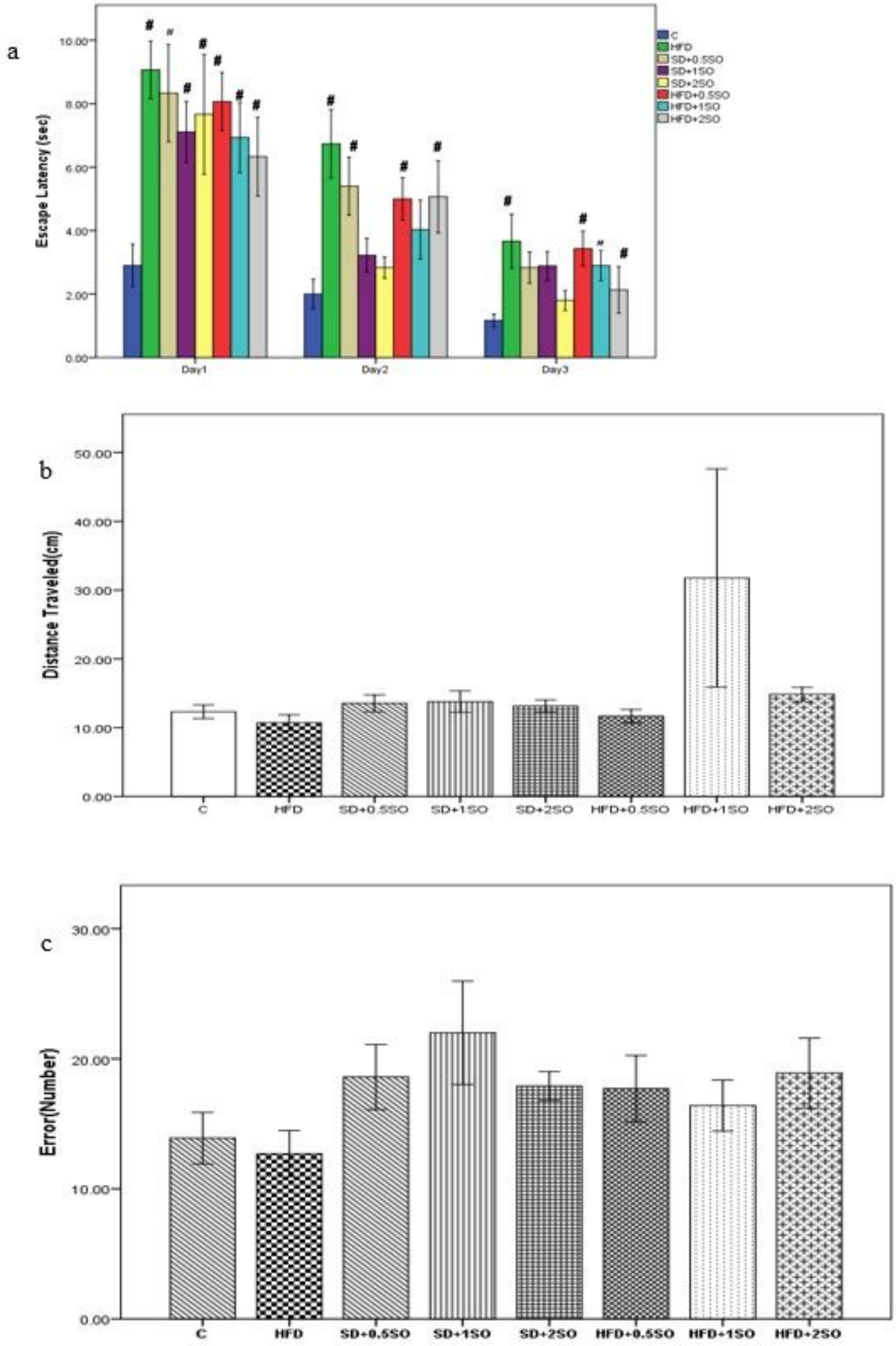

Figure 3

(a) The comparison of the escape latency to reach the target zone during training days, (b) distance traveled in the target zone on the test day, and (c) the number of errors in finding the escape box on the test day in the Barnes test ( $\mathrm{n}=10$ each group). Data are displayed as mean \pm standard deviation. $\# \mathrm{P}<0.05$ compared with the control group. 


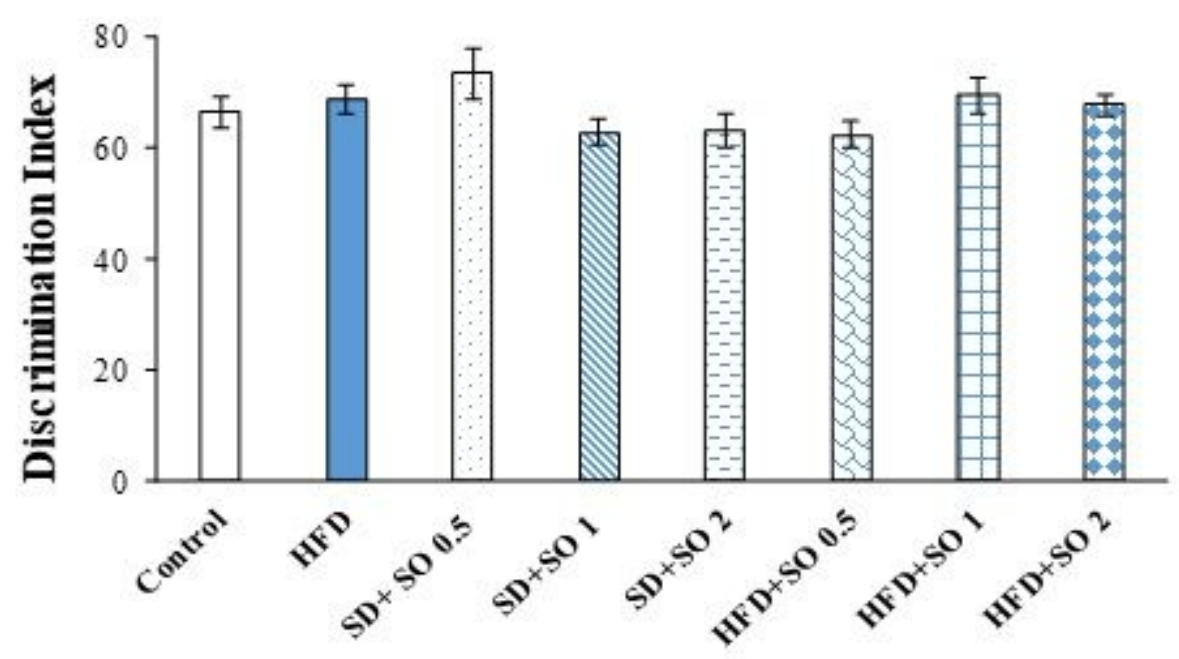

Figure 4

Object recognition index in the test phase of the novel object recognition (NOR) test ( $n=10$ each group). Data are displayed as mean \pm standard deviation. 

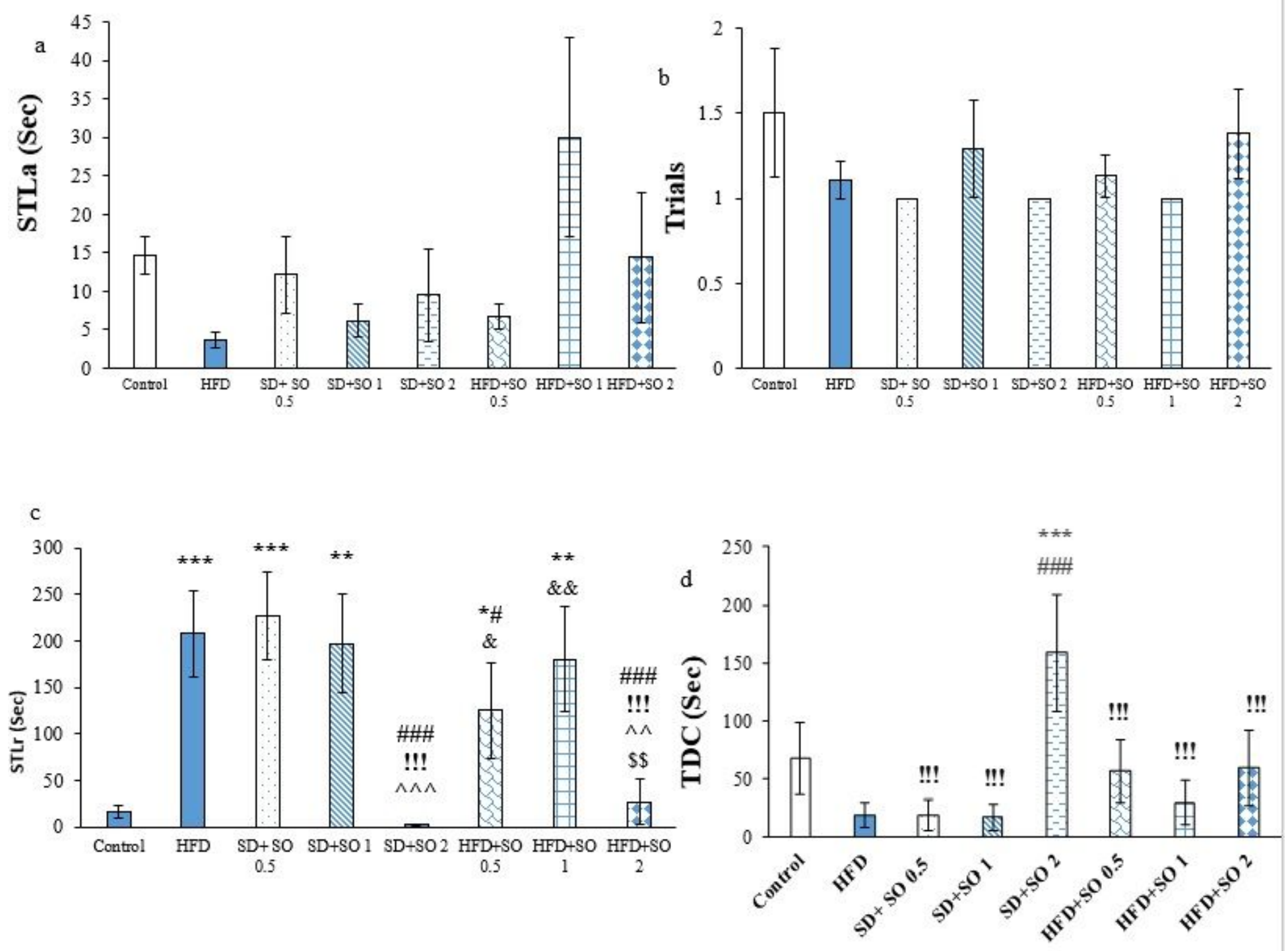

Figure 5

(a) Step-through latency (STLa) in the first acquisition trial, (b) number of shocks received in the learning phase, (c) the step-through latency in the retention trial (STLr), (d) the time spent in the dark compartment in the retention trial (TDC). Data are displayed as mean \pm standard deviation. ${ }^{*} \mathrm{P}<0.05, * * \mathrm{P}<0.01$ and $\star \star \star P<0.001$ compared with the control group. \#P $<0.05$ and \#\#\#P $<0.001$ compared with the HFD group. !! $\mathrm{P}<0.001$ compared with the SD $+\mathrm{SO}(0.5 \mathrm{ml} / \mathrm{kg})$ group. \%P $<0.001$ and ${ }^{\wedge \wedge} \mathrm{P}<0.01$ compared with the $\mathrm{SD}+\mathrm{SO}(1 \mathrm{ml} / \mathrm{kg})$ group. $\$$ P $<0.01$ compared with the HFD + SO $(2 \mathrm{ml} / \mathrm{kg})$ group. 


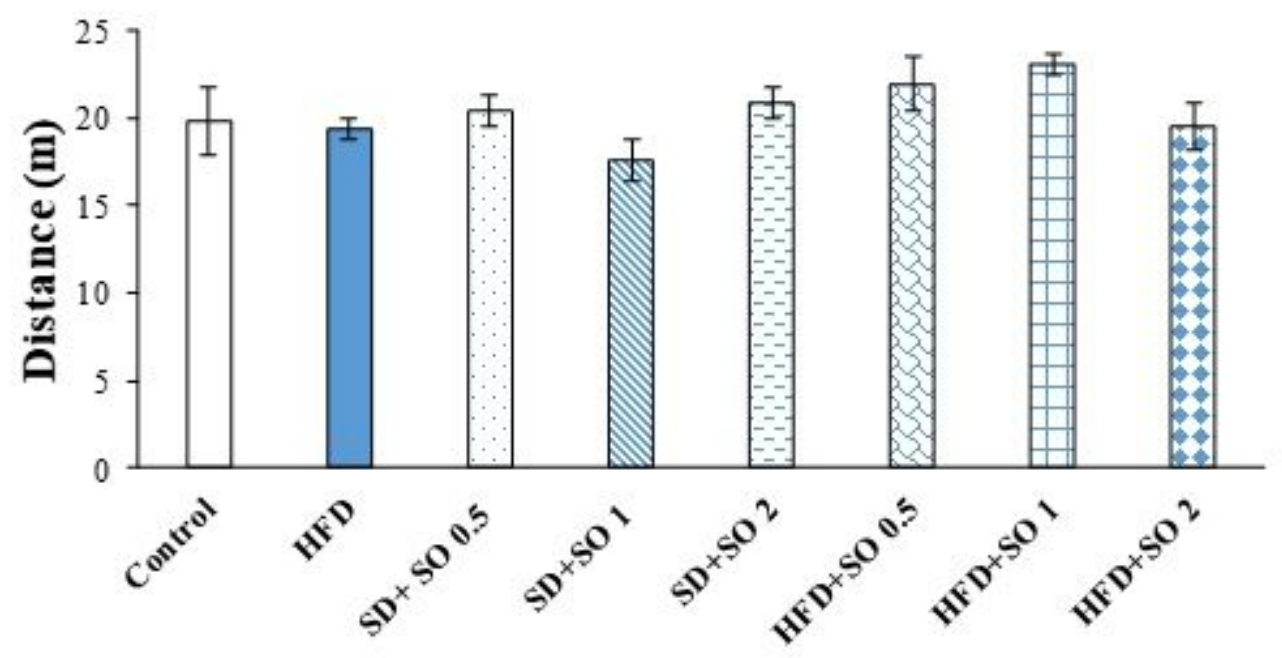

Figure 6

The comparison of the distance traveled in the motor activity test ( $\mathrm{n}=10$ each group). Data are displayed as mean \pm standard deviation. 
a
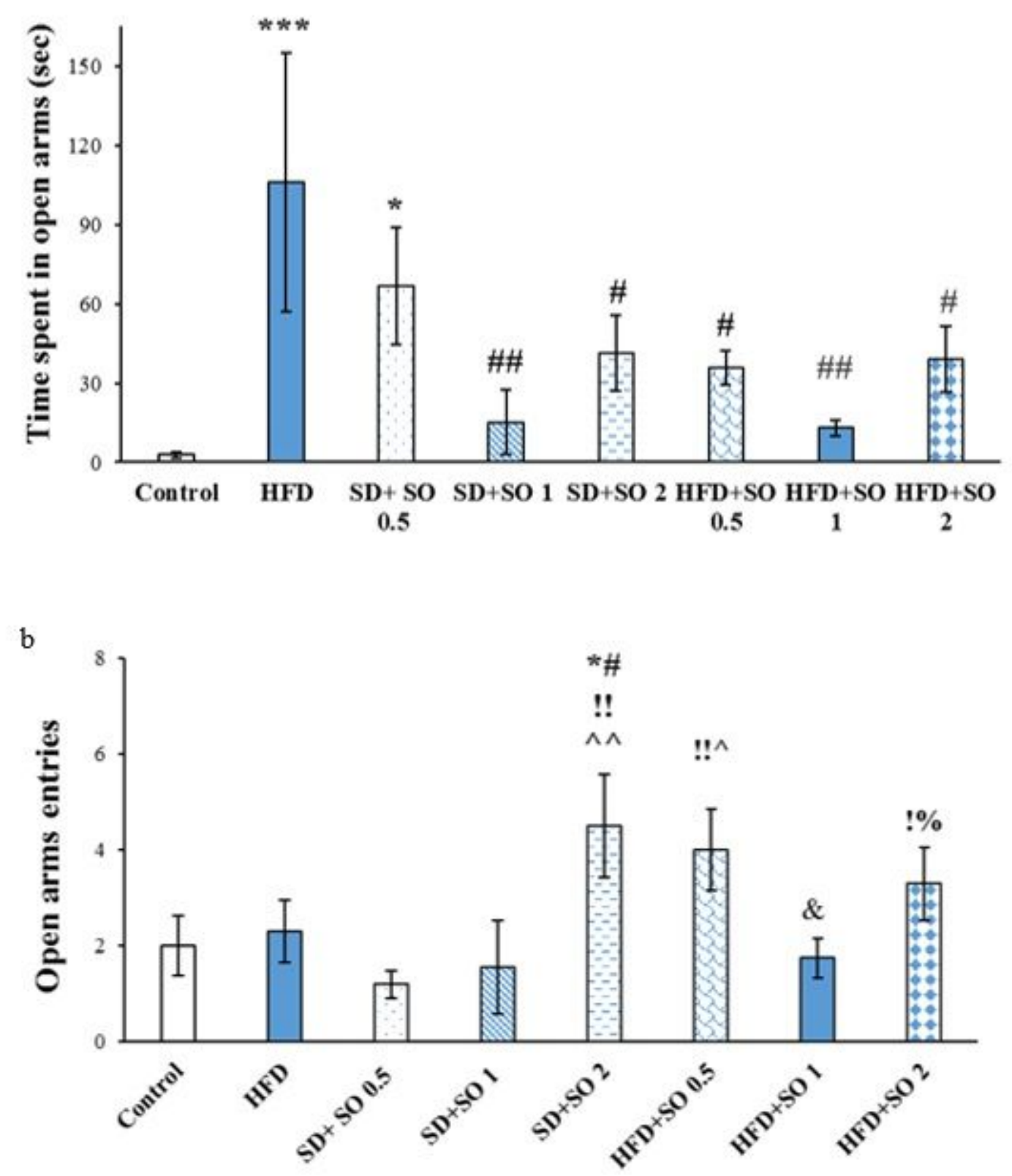

Figure 7

Effects of sesame oil and HFD on (a) time spent in open arms and (b) the number of entries in open arms in elevated plus-maze ( $n=10$ each group). Data are displayed as mean \pm standard deviation. ${ }^{*} P<0.05$ and ${ }^{\star \star *} P<0.001$ compared with the control group. \#P $<0.05$ and \#\#P $<0.01$ compared with the HFD group. !!P $<0.01$ compared with the $S D+S O(0.5 \mathrm{ml} / \mathrm{kg})$ group. ${ }^{\wedge}{ }^{\wedge} \mathrm{P}<0.01$ compared with the $\mathrm{SD}+\mathrm{SO}$ $(1 \mathrm{ml} / \mathrm{kg})$ group. \& \& $\mathrm{P}<0.01$ compared with the HFD $+\mathrm{SO}(0.5 \mathrm{ml} / \mathrm{kg})$ group. $\% \mathrm{P}<0.05$ compared to the $\mathrm{HFD}+\mathrm{SO}(1 \mathrm{ml} / \mathrm{kg})$ group. 

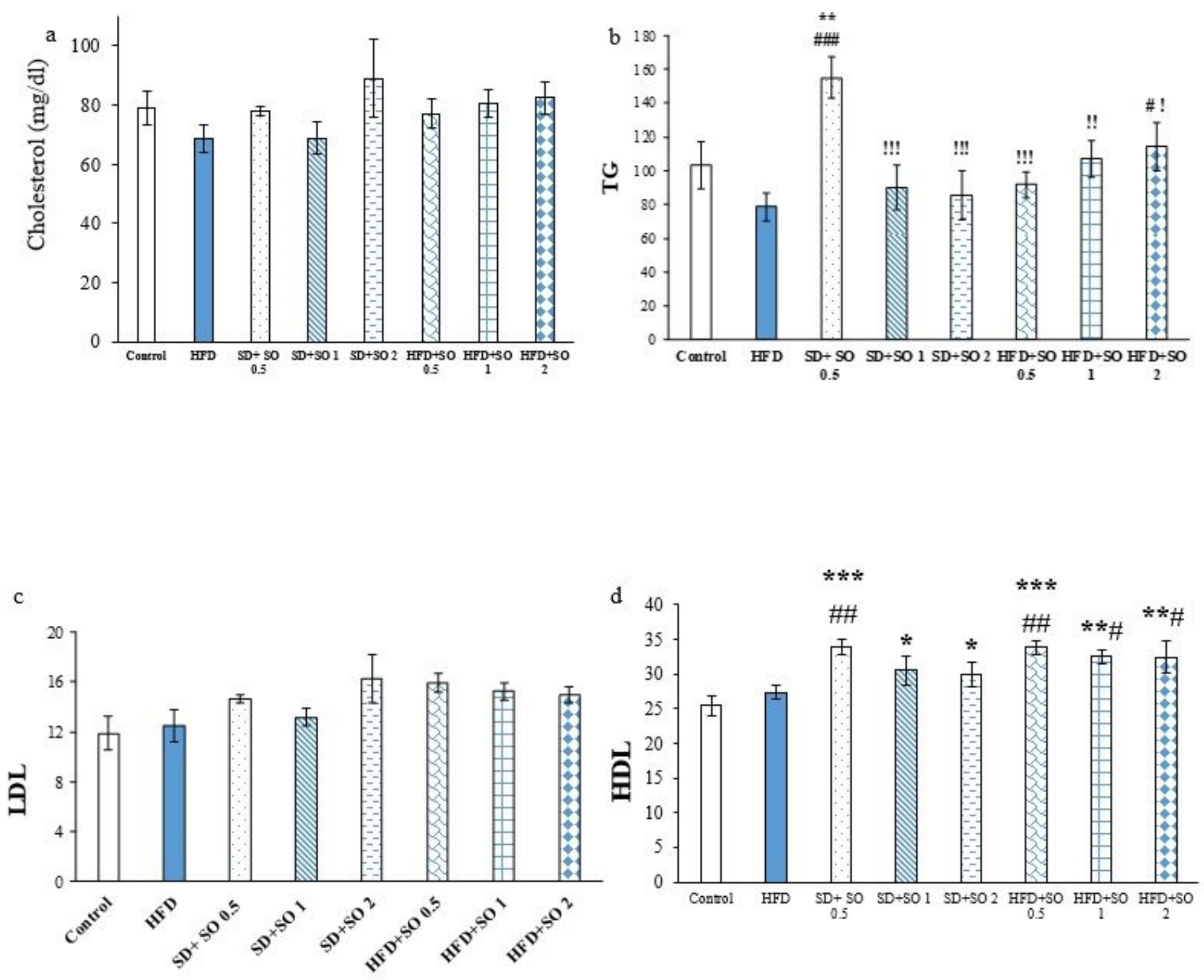

\section{Figure 8}

Comparison of (a) cholesterol, (b) triglyceride, (c) low-density lipoprotein (LDL), and (d) high-density lipoprotein (HDL) levels. Data are displayed as mean \pm standard deviation ( $n=10$ each group). ${ }^{*} P<0.01$ Compared with control group. \#P<0.05 and \#\#P $<0.01$ compared with HFD group. !P $<0.05$, ! P $<0.01$, and !!!P $<0.01$ compared with the SD+SO $(0.5 \mathrm{ml} / \mathrm{kg})$ group. 

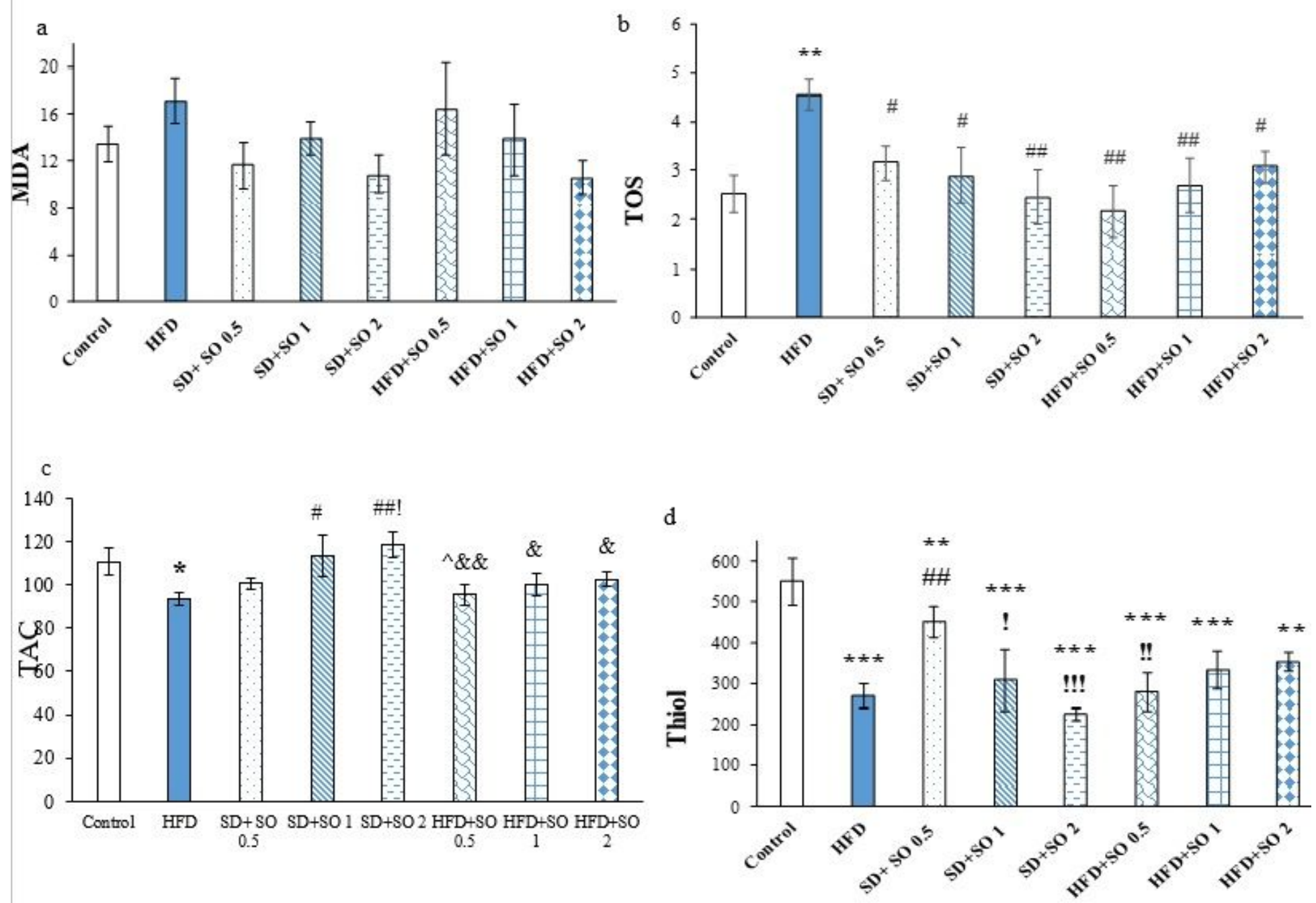

Figure 9

Comparison of the serum levels of (a) malondialdehyde (MDA) (b) total oxidant status TOS, (c) total antioxidant capacity (TAC) and (d) total thiol. Data are displayed as mean standard deviation. ${ }^{*} \mathrm{P}<0.01$ compared with control group. \#P<0.05 and \#\#P<0.01 compared with HFD. !P $<0.05$ compared with the $\mathrm{SD}+\mathrm{SO}(0.5 \mathrm{ml} / \mathrm{kg})$ group.^ $\mathrm{P}<0.05$ compared with the $S D+S O(1 \mathrm{ml} / \mathrm{kg})$ group. \& $\mathrm{P}<0.05$ and \&\&P $<0.01$ compared with the SD+SO $(2 \mathrm{ml} / \mathrm{kg})$ group. 